\title{
コンパクト放射光源としての極短周期アンジュレータの開発
}

山本 樹 1,2

1高エネルギー加速器研究機構 放射光科学研究施設 (テ305-0801 茨城県つくば市大穂1-1)

2総合研究大学院大学 物質構造科学専攻 (₹305-0801 茨城県つくば市大穂1-1)

\section{Development of a Very Short Period Undulator as a Compact Synchrotron Light Source}

\author{
Shigeru YAMAMOTO ${ }^{1,2}$ \\ ${ }^{1}$ Photon Factory, High Energy Accelerator Research Organization, KEK, 1-1 Oho, Tsukuba, Ibaraki 305-0801 \\ ${ }^{2}$ Department of Materials Structure Science, SOKENDAI (The Graduate University for Advanced Studies), 1-1 Oho, Tsukuba, Ibaraki 305-0801
}

(Received October 20, 2016)

\begin{abstract}
A novel method for fabricating undulator magnets having very short periods has been explored and developed. Magnet plates of 4-mm period length have been successfully fabricated. A method of connecting these plates to fabricate longer undulators has also been successfully developed. The measured undulator field is satisfactory for producing undulator radiation comparable to that from an ideal undulator field with the same period length.
\end{abstract}

Key Words: Synchrotron radiation, Undulators, Free electron lasers

1. はじめに

放射光光源の進歩においては研究分野の拡大のため に, より短い波長の光源の開発が常に要求されてきた。 この時アンジュレータは放射の生成装置として重要な役 割を果たす。鉛直 $(y-)$ 方向のアンジュレータ磁場 (周期 長 $\left.\lambda_{\mathrm{u}}\right), B_{\mathrm{y}}=B_{0} \sin \left(2 \pi \mathrm{z} / \lambda_{\mathrm{u}}\right)$ の中を $\mathrm{z}-$ 方向に進行する電子は 水平 $(x-z)$ 面内で蛇行運動を行う. アンジュレータ軸上 放射の $k$ 次の波長 $\lambda_{\mathrm{k}}$ は, 次式に示す様に $\lambda_{\mathrm{u}}$ に比例し, 電 子エネルギー(ローレンツ因子) $\gamma$ の自乗に逆比例して増 減する。

$$
\lambda_{\mathrm{k}}=\frac{\lambda_{\mathrm{u}}}{2 k \gamma^{2}}\left(1+\frac{K^{2}}{2}\right)
$$

ここで, $K=93.4 B_{0}(\mathrm{~T}) \lambda_{\mathrm{u}}(\mathrm{m})$ はアンジュレータの偏向定 数であり $\lambda_{\mathrm{u}}(\mathrm{m})$ と磁場強度 $B_{0}(\mathrm{~T})$ によって定義される。 従って, 与えられた $\gamma$ の電子からより短波長の放射を得 るには，より短周期の磁場が必要になる。

高エネルギー加速器研究機構・放射光科学研究施設 (KEK-PF)においては, より短波長の放射光を得るため に真空封止アンジュレータの開発を行って来た。最初の 成功は6.5 GeV PF-AR (Photon Factory- Accumulation Ring) に設置された磁場周期長40 $\mathrm{mm}$ の真空封止アンジュレー タによって達成された ${ }^{1,2)}$ 。このブレークスルーによっ て, $14.4 \mathrm{keV}$ 放射光を3次のアンジュレータ放射とし て実現することが可能になった。PF-ARよりエネルギー の低いPF2.5 GeVリングにおいても, 同程度の短波長放
射を実現するためにShort Gap Undulator (SGU) の開発を 行い実用化した ${ }^{3,4)}$. PFに設置した4台のSGUは12 mmか ら $18 \mathrm{~mm}$ の周期長を持ち，12 keVのX線を生成できるよ うに設計されている.

上記の真空封止アンジュレータ開発の成功を踏まえ て, 近年我々は更に低いエネルギーの光源加速器におい て，より低次のアンジュレータ放射を用いつつ，より高 いエネルギーの放射の実用化を目指して, “極短周期”ア ンジュレータの研究開発を行っている ${ }^{5-11)}$ 。ここで, “極 短周期” とは通常型アンジュレータの周期長 (数 $\mathrm{cm}$ )の約 $1 / 10$ の周期長とする。本研究では周期長 $4 \mathrm{~mm}$ 目標に 設定し, 板状の $\mathrm{NdFeB}$ 製磁性素材に, 周期的交番磁気回 路を高精度・高強度で書き込む多極着磁方式の開発を 行ってきた．着磁後に(真空中で)対向させた一対の磁石 板の間の隙間(磁石ギャップ)にアンジュレータ磁場を生 成することができる。

極短周期アンジュレータでは周期長の短縮に伴い，そ れ自体が非常にコンパクトなものになる，従って，装置 自体の大幅なコンパクト化を目指すレーザー航跡場加速 方式に基づく光源加速器との相性は非常に良い. 本稿で は極短周期アンジュレータの原理と開発の現時点での到 達点について報告する。

\section{2. 極短周期長アンジュレータ磁場生成の原理}

通常，アンジュレータの磁気回路形成は，非常に平面 度・平行度の良いガーダー上に, 高精度に着磁された 


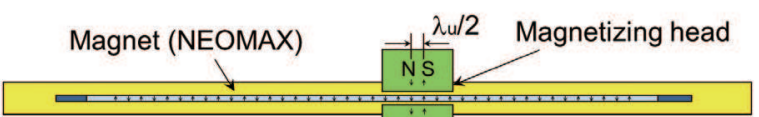

Stepwise scan of $\lambda u / 2 \longrightarrow$ NS $\quad$ Linear motor

$\lambda u$ scan $=1^{\text {st }}$ step of $\lambda u / 2 \quad N S+2^{\text {nd }}$ step of $\lambda u / 2$ S N

Fig. 1 Multi-pole magnetization of a thin magnet plate using a linear motor.

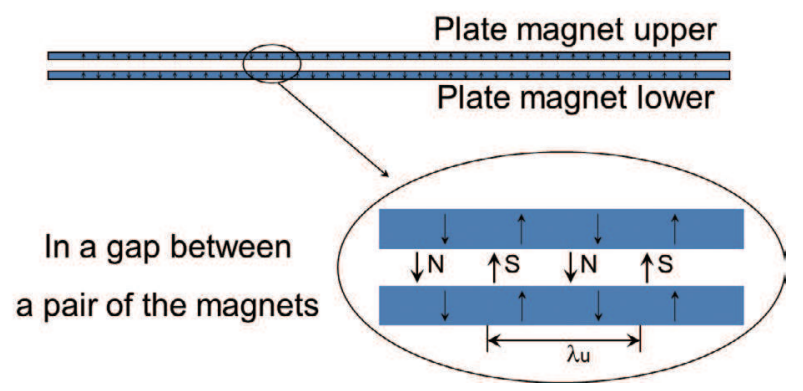

Fig. 2 Formation of an undulator field with perpendicular magnetization.

(着磁強度のばらつきの少ない) 寸法精度も非常に高い磁 石ブロックを整列させることによって達成される。従っ て, 通常型アンジュレータにおいて周期長の短縮を試み る場合, 高精度に着磁された磁石ブロックの寸法をその (相対)精度を保ちつつ縮小することが必要になる。しか し, 周期長が現在の通常の值から非常に小さくなって, 例えば10 mmを下回るようになると, 上記の精度を保ち つつ磁石ブロックを製作することは難しくなり，この方 式は成立しなくなる，更に磁石ブロックの組立・設置に 用いるボルト等の部品が小さくなりすぎて使用に耐えな くなる.

上述の通常アンジュレータの製作方式とは対照的に, 我々は板状磁石素材に多極着磁を施して極短周期アン ジュレータ磁石を作成するための全く新しい方式を開発 してきた ${ }^{5-11)}$ 。ここでは, Fig. 1 に概念的に示した多極 着磁法を用いて, 板状磁石の着磁を行った. Fig. 1 に示 した方式では着磁方向は磁石板面に垂直となるように設 定されている。ここではこの方式を垂直着磁方式と呼ぶ が, この場合の幾何学は磁気記録媒体の垂直磁気記録方 式と同様である. もう一つ(水平着磁型)の幾何学も可能 である ${ }^{5-7)}$ 。この場合は水平磁気記録方式と同様, 着磁 は磁石素材板表面に平行に行われる.

磁石素材には, 日立金属(株)製のNMX-39EH(残留磁 束密度 $B_{\mathrm{r}}=12 \mathrm{kG}$ ， および保磁力 $i H \mathrm{c}=25 \mathrm{kOe}$ )を採用し た. 現在 2 種類の形状の磁石板を製作することができ る。第1の形状は, 長さ $100 \mathrm{~mm}$, 幅 $20 \mathrm{~mm}$, 厚さ $2 \mathrm{~mm}$ ある、第2のものは，長さ $152 \mathrm{~mm}$ で幅と厚さは同一であ る。この磁石板は一対の着磁ヘッドに挟まれて, 長手方 向にリニアモータによってステップ状に送られながら着 磁される，着磁へッドには1極(半周期)磁場を生成でき る電磁石を製作して用いた。リニアモータによるステッ プ送り幅は周期磁場の半周期分 $(2 \mathrm{~mm})$ に設定されてい る。着磁へッドに印加するパルス電流の方向を, 磁石板
を送る際のステップ毎に反転することで周期長 $4 \mathrm{~mm}$ の アンジュレータ磁場を生成した。このようにパルス電流 を着磁へッド電磁石に印加することで, そのステップ毎 に磁石板中にN極と $\mathrm{S}$ 極を交互に周期的に連続して書き 达むことができるようになった，着磁後の一対の磁石板 を互いに対向させることによって，磁石間の狭い隙間 (ギャップ)に周期的アンジュレータ磁場が形成される (Fig. 2) $)^{5-11)}$.

着磁終了後の磁石板をFig. 3 に示した：100 mm長磁 石；Aおよび $\mathrm{B}^{7,8)}, 152 \mathrm{~mm}$ 長磁石； E1および $2^{9-11)}$ 。磁 石表面は, 加速器真空中にこの磁石を持ち込む際の真空 封止のためにTiNコート処理を施した。Fig. 3 では吸着 事故防止のために，磁石をアクリル樹脂製のケースに収 納して示した。着磁後の磁場のパターンを示すために, BとE2の磁石板については磁極面に磁性流体シートを置 いて観察できるようにしてある. Fig. 3 の着磁例は, 周 期長 $4 \mathrm{~mm}$ のアンジュレータ磁場として25周期から38周 期が放射光実験の実用上の使用に耐える周期数であるな らば, “モノリシック”アンジュレータ磁石も利用できる ようになったことを示している。ささらに, これらの板状 磁石の製作はアンジュレータの小型化・重量削減にも有 用であり，最終的にはNd-Fe-B磁石の主要成分である希 土類元素(特に重希土類)を含む重要な資源の保全にも有 効である。

\section{3. 極短周期長アンジュレータ磁場の生成と評価}

上述の手順で作成した一対の板状磁石を互いに平行に 対向して配置すると, 磁石板間の狭いギャップにアン ジュレータ磁場が生成される(Fig. 2). 生成されたアン
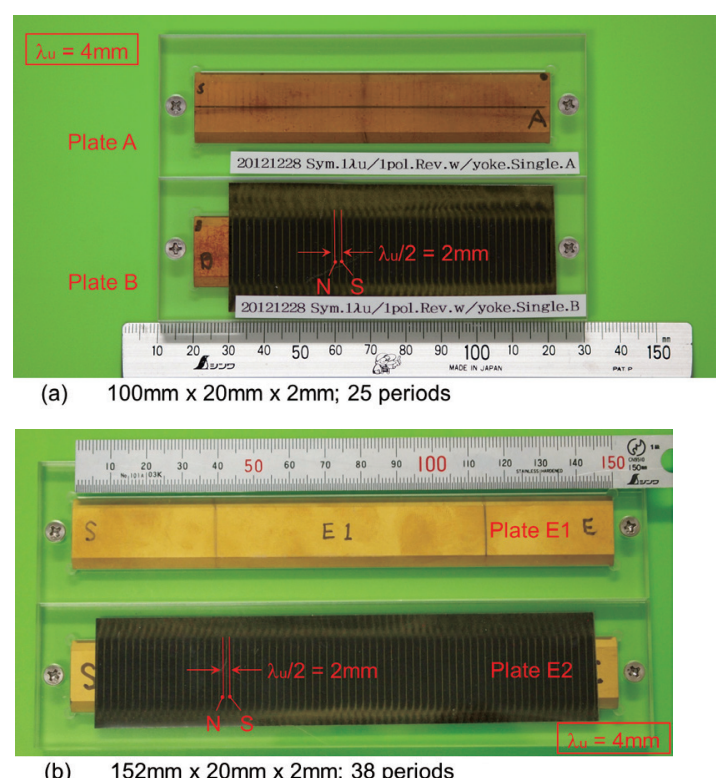

Fig. 3 Magnetized plates with period length of $4 \mathrm{~mm}$. Magnetized plates coated with TiN. A pair of these plates is placed in opposition to form the undulator field; (a) plates A and B are $100 \mathrm{~mm}$ long, and (b) $\mathrm{E} 1$ and $\mathrm{E} 2$ are $152 \mathrm{~mm}$ long. 

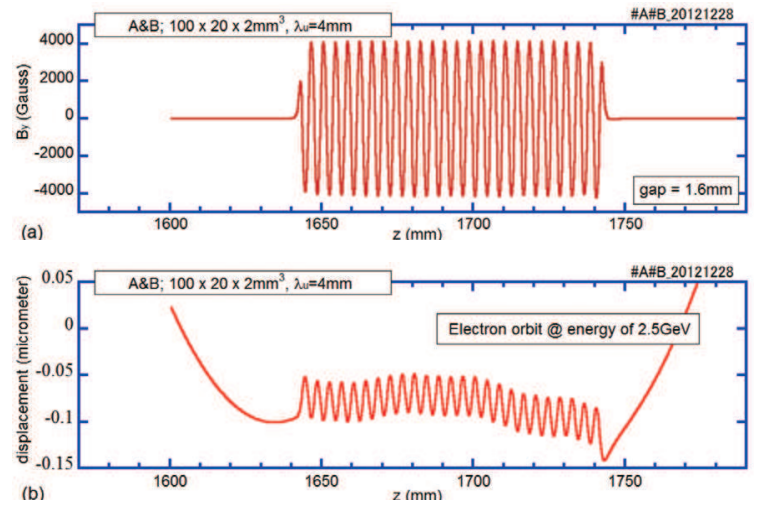

Fig. 4 Magnetic field of an undulator $100 \mathrm{~mm}$ long. (a) Undulator field with a period length of $4 \mathrm{~mm}$ measured with a gap of $1.6 \mathrm{~mm}$, and (b) orbit of an electron with a $2.5-\mathrm{GeV}$ energy.

ジュレータ磁場のホール素子による測定結果を以下に示 す. 現在測定は固定された $1.6 \mathrm{~mm}$ のギャップに対して 行い, ホール素子は厚さ $1.3 \mathrm{~mm}$ 銅製ホルダに装着し て使用した。 ホール素子の空間分解能(感受領域)は0.05 $\times 0.05 \mathrm{~mm}^{2}$ である.

磁石ギャップ $g$ に対する周期長 $\lambda_{\mathrm{u}}$ の比 $g / \lambda_{\mathrm{u}}$ を指標にす る場合, 今回の $g=1.6 \mathrm{~mm}$ は $g / \lambda_{\mathrm{u}}=0.4$ に相当する. KEKPFにおける真空封止アンジュレータでは, $\lambda_{\mathrm{u}}=40 \mathrm{~mm}$ に対して $g / \lambda_{\mathrm{u}}=0.25-0.5^{1)}$ ，また $\lambda_{\mathrm{u}}=12 \mathrm{~mm}$ に対して $g / \lambda_{\mathrm{u}}=0.33-0.67^{4)}, \lambda_{\mathrm{u}}=16 \mathrm{~mm}$ に対して $g / \lambda_{\mathrm{u}}=0.25-0.5^{3)}$ で ある。従って磁場評価のためには, $g=1.6 \mathrm{~mm}$ は不適切 ではないが，極短周期アンジュレータの実用時にはより 狭いギャップが要求される.

板状磁石に対して行った磁場測定の結果をFig. 4 と Fig. 5 に示した. Fig. 4 では100 mm長磁石板のペア(Aと B：Fig. 3(a) 参照)に対して，ギャップ1.6 mmにおけるア ンジュレータ磁場 (Fig. 4(a)) と, その磁場中を通過する エネルギー2.5 GeVの電子の軌道 $($ Fig. 4 (b)) を示してい る ${ }^{7,8)}$. ギャップ1.6 mmにおいて約 $4 \mathrm{kG}$ のアンジュレー 夕磁場 $\left(B_{0}\right)$ を達成した。着磁へッドと磁石板のアンジュ レータ軸方向の位置関係を調整することにより, 軸方向 の磁場分布は中心に対してほぼ対称となっている. 現時 点で特に調整を行っていない端部を除いて, 全体的に見 て良好なアンジュレータ軌道を得ることができた。

同様に, $152 \mathrm{~mm}$ 長磁石板のペア (E1とE2：Fig. 3(b) 参 照)に対する， $g=1.6 \mathrm{~mm}$ における磁場(Fig. 5(a))とその 磁場中を通過するエネルギー2.5 GeVの電子の軌道 (Fig. 5(b))を示している, ${ }^{9,10)}$. ギャップ1.6 mmにおける 到達磁場は，同じく約 $4 \mathrm{kG} ゙$ あ。.この磁石板E1 とE2 に対しては, アンジュレータ軸中心に対して反対称の磁 場分布が得られるように着磁ヘッドと軸方向の位置関係 を調整した. Fig. 5 (b)に示した磁場中の電子軌道からも わかるように，非常に良好な磁場を得ることができた。

$100 \mathrm{~mm}$ 長磁石に加えて152 mm長磁石の製作ができる ようになったことは, “モノリシック”アンジュレータ磁 石によって，より長いアンジュレータ磁場を生成する試 みの一つの成功例である。しかし, 現在開発している薄
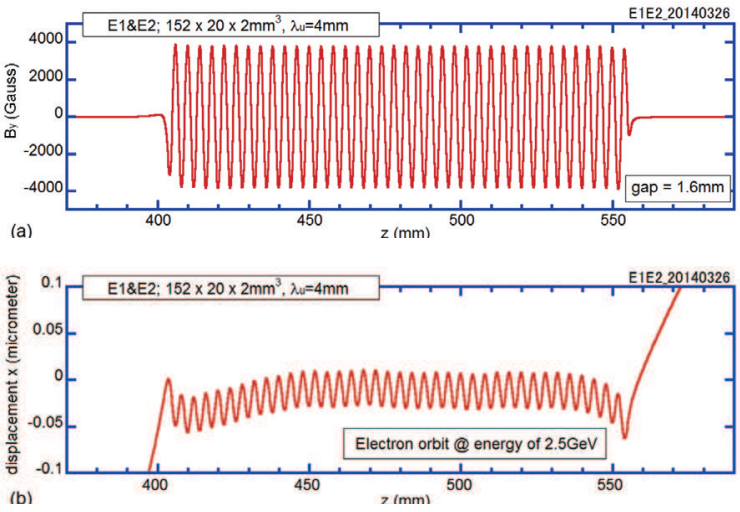

Fig. 5 Magnetic field of an undulator $152 \mathrm{~mm}$ long. (a) Undulator field with a period length of $4 \mathrm{~mm}$ measured with a gap of $1.6 \mathrm{~mm}$, and (b) orbit of a 2.5-GeV electron.
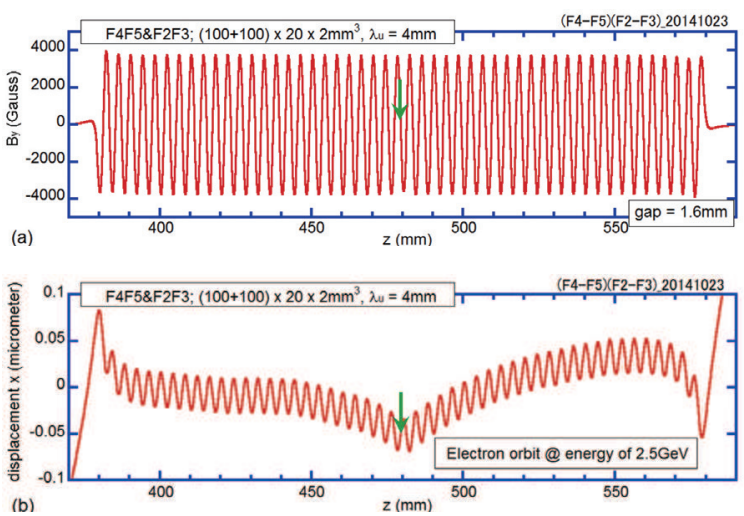

Fig. 6 Field of an undulator $200(100+100) \mathrm{mm}$ long. (a) Undulator field with a period length of $4 \mathrm{~mm}$ measured with a gap of $1.6 \mathrm{~mm}$, and (b) orbit of a 2.5-GeV electron. After independent magnetization of the plates, plates F2 and F3 are connected and then placed in opposition to the other plates F4 and F5.

い板状磁石の製作においては長さに限界が存在し, 厚さ が2 mmまたはそれ以下の場合, $200 \mathrm{~mm}$ を超える長さの 磁石を製作することは容易ではない，従って，板状磁石 をアンジュレータ軸方向に連結する方法を開発する必要 がある. Fig. 6 に示したのは, $100 \mathrm{~mm}$ 長の磁石板の連結 を試みた最初の例である ${ }^{9,10)}$ 。ここでは, 反対称磁場分 布を持つように着磁した100 mm長の磁石板F4およびF5 を単純に軸方向に連結し, 同様に着磁し連結した磁石板 F2およびF3と上下に対向させた，4枚の磁石板の着磁は 各々個別に行った。磁場測定は同じくギャップ1.6 mm において行った(Fig.6(a)). Fig.6の例では，個々の磁 石を全く独立に着磁し, 連結部分の調整は全く行ってい ないにも拘わらず, 連結点 (図中の緑色矢印)に拈ける磁 場の不整は非常に小さい. 電子軌道 $($ Fig. 6(b)) も, 長さ $200(100+100) \mathrm{mm}$ のアジュレータとして適切なもの であり, 連結部分の小さなキックは重要でない.

上記の状態を改善し, より良好なアンジュレータ磁場 を得るために, 連結すべき磁石を軸方向に一体にして連 結したまま着磁を行う方法を開発した ${ }^{11)}$. 2組の100 mm 

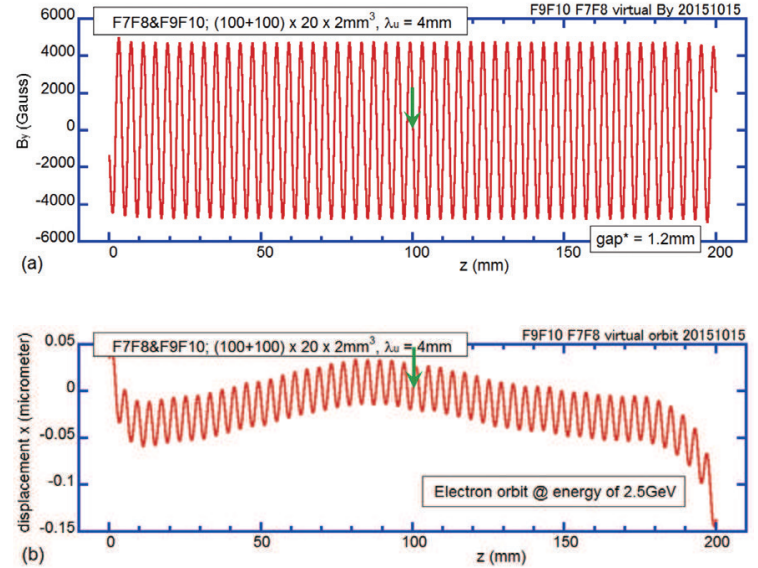

Fig. 7 Field of an undulator $200(100+100) \mathrm{mm}$ long. (a) Undulator field with a period length of $4 \mathrm{~mm}$ measured with a gap of $1.6 \mathrm{~mm}$, and (b) orbit of a 2.5-GeV electron. Plates F7 and F8 are connected longitudinally then magnetized, and then placed in opposition to the other plates F9 and F10 magnetized in the same way.

長の磁石板F9およびF10とF7およびF8を一体として着磁 し，その後対向させて行った磁場測定の結果を示した (Fig.7(a))。F9およびF10（またはF7およびF8）の磁場分 布は, Fig. 6 の例と同じく軸方向に反対称的である. 磁 場測定は $g=1.2 \mathrm{~mm}$ において行った。連結点(Fig.7 中の 緑色矢印)に扮ける磁場不整は非常に小さい。磁場不整 の影響がより顕著に表れるはずの電子軌道 (Fig. 7(b))で 見ても，連結点における磁場不正は非常に小さなものに 抑えられている。長さ200 $(100+100) \mathrm{mm}$ のアンジュ レータとして, Fig. 6 の場合よりも更に良好な磁場およ び電子軌道が得られたことが判る ${ }^{11)}$.

\section{4. 実測磁場に基づく放射の評価}

上述の実測磁場に基づいて放射光の光束密度スペクト ルの計算を行った。電子エネルギーが $2.5 \mathrm{GeV}$ ，エミッ タンスおよびエネルギー広がりが共に零の場合に求めた スペクトルを, 同強度の理想磁場の時のスペクトルと比 較してFig. 8 およびFig. 9 に示した. Fig. 8 には100 mm 長および $152 \mathrm{~mm}$ 長の“モノリシック”アンジュレータか らの放射特性を, Fig. 9 には100 mm長の磁石板2枚を連 結した連結型200 mm長アンジュレータからの放射特性 を示した。

Fig. 4(a)およびFig. 5(a)に示した“モノリシック”アン ジュレータを通過する電子からの放射スペクトル (Fig. 8 (a) $)^{7,8)}$ およびFig. 8(b) $)^{9,10)}$ の赤線) は, アンジュレー夕基 本波の領域では理想磁場 (青線)からの放射スペクトルと 比べて同等の性能を持つ. 10-15 keVの光子エネルギー の領域では放射光実験の光源として有用である. Fig. 6 (a)およびFig. 7(a)に示した連結型200 mm長アンジュ レータ磁場を通過する電子からの放射スペクトル (Fig. 9 (a) ${ }^{9,10)}$ およびFig. 9(b) ${ }^{11)}$ の赤線) も同様に，基本波の領域 では理想磁場(青線)からの放射スペクトルと同等の性能
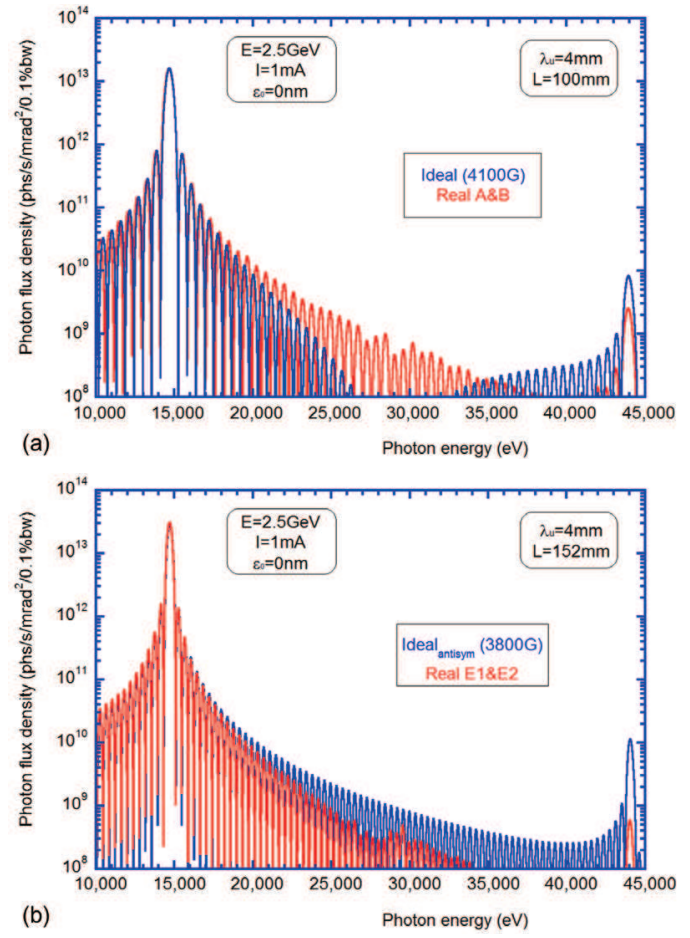

Fig. 8 Comparison of flux density spectra. The spectrum calculated on the basis of the measured field compared to that of the ideal field for the $2.5-\mathrm{GeV}$ electron beam with zero emittance and zero energy spread; (a) spectrum for the 100-mm plates (Fig. 4), and (b) for the 152-mm plates (Fig. 5).
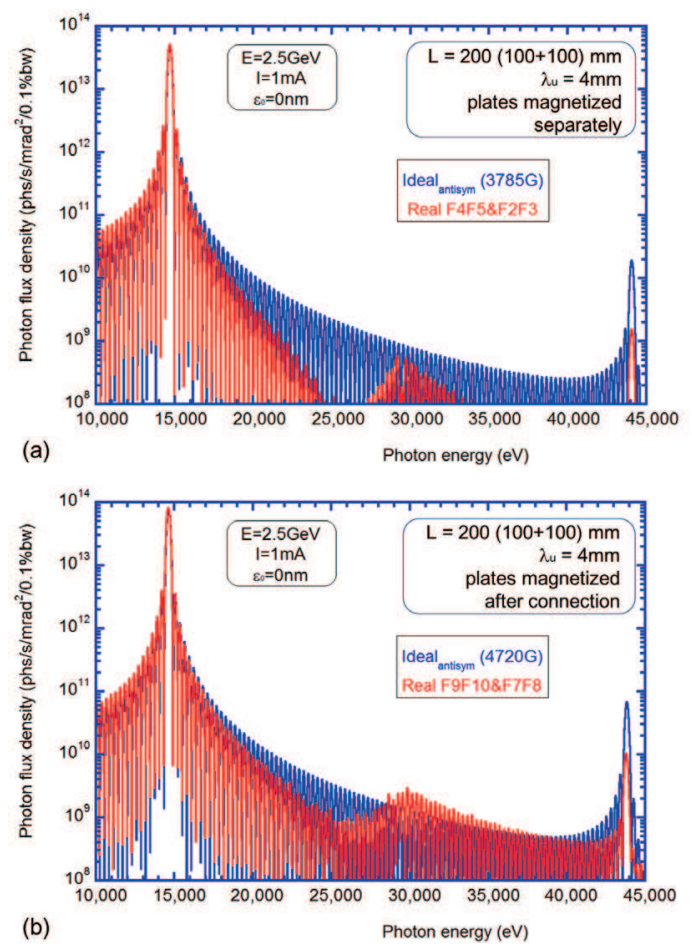

Fig. 9 Comparison of flux density spectra. The spectrum calculated on the basis of the measured field compared to that of the ideal field for the $2.5-\mathrm{GeV}$ electron beam with zero emittance and zero energy spread; (a) the case of separately-magnetized plates (Fig. 6), and (b) the case of plates magnetized after connection (Fig. 7). 
を持つ. Fig. 6(b)に見られる連結部の磁場不整による小 さなキックは, 磁石の連結数がこの例の様に少ない場合 は影響が小さいことが判る。しかし，連結数の多い長尺 のアンジュレータ磁石を製作する場合には，連結部の磁 場不整効果が累積することを避けるために, Fig.7(b)に 示した滑らかで良好な軌道を与える連結着磁法の採用が 重要になる。

上述の成果は，極短周期アンジュレー夕開発のための 主要な問題点を解決することができたことを示してい る。アンジュレータ磁石を連結して長尺化するための方 式の開発においても，明確な成果を得ることができた。 実用機の開発にはさらに, 着磁強度と精度の向上を達成 し，アンジュレータ両端部の適切な磁場強度を達成する ための着磁法の改良が必要になる。これらを解決した上 で, 現在一方で開発中の, 精密ギャップ駆動機構と組み 合わせることで, 高性能の実在電子ビームを用いた極短 周期アンジュレータからの放射の観測と評価の実験を実 現したいと考えている。

\section{謝 辞}

本研究は, 一部において, JSPS科研費24651107および 26246044の助成を受けています。また，同じく一部にお
いて, 内閣府革新的研究開発推進プログラムImPACT 「ユビキタス・パワーレーザーによる安全・安心・長寿 社会の実現」の支援を戴いております。暖かいご支援と 卓越したご指導を戴いておりますプロジェクトマネー ジャーの佐野雄二博士に篤く御礼申し上げます。

\section{参考文献}

1) S. Yamamoto, T. Shioya, M. Hara, H. Kitamura, X. W. Zhang, T. Mochizuki, H. Sugiyama, and M. Ando: Rev. Sci. Instrum. 63 (1992) 400.

2) S. Yamamoto, X. W. Zhang, H. Kitamura, T. Shioya, T. Mochizuki, H. Sugiyama, M. Ando, Y. Yoda, S. Kikuta, and H. Takei: J. Appl. Phys. 74 (1993) 500.

3) S. Yamamoto, K. Tsuchiya, and T. Shioya: AIP Conf. Proc. 879 (2007) 384

4) S. Yamamoto, K. Tsuchiya, H. Sasaki, T. Aoto, and T. Shioya: AIP Conf. Proc. 1234 (2010) 599.

5) S. Yamamoto: Journal of Phys.: Conf. Ser. 425 (2013) 032014.

6) 山本 樹：第10回日本加速器学会年会プロシーディングス (2013) SAOT11 86.

7) S. Yamamoto: Proc. IPAC2014 (Dresden, 2014) WEOAA02 1845.

8) S. Yamamoto: Synchrotron Radiation News 28 (2015) 19

9) 山本 樹：第12回日本加速器学会年会プロシーディングス (2015) FROM04 187.

10) S. Yamamoto: AIP Conf. Proc. 1741 (2015) 020029.

11) 山本 樹：第13回日本加速器学会年会プロシーディングス (2016) TUP066 1035. 